\title{
17. Über die Verschiedenheit der Blütenfarben von Hanashobu (Iris ensata Thunb.) in ihren Assoziationen.
}

\author{
Von Manabu Mryoshi, M.I.A.
}

(Comm. Feb. 13, 1939.)

In meinen früheren Mitteilungen habe ich darauf hingewiesen, dass die assoziationsbildende Hanashobu (Iris ensata Thunb.) in bezug auf die Farbe der Blüten sich in drei Gruppen einteilen lässt. 1. mit purpurroter Sippe, 2. mit violetter Sippe, 3. mit gemischten Sippen. ${ }^{1}$

Weitere Studien über die Verbreitung dieser Sippen fasse ich in folgender Tabelle zusammen.

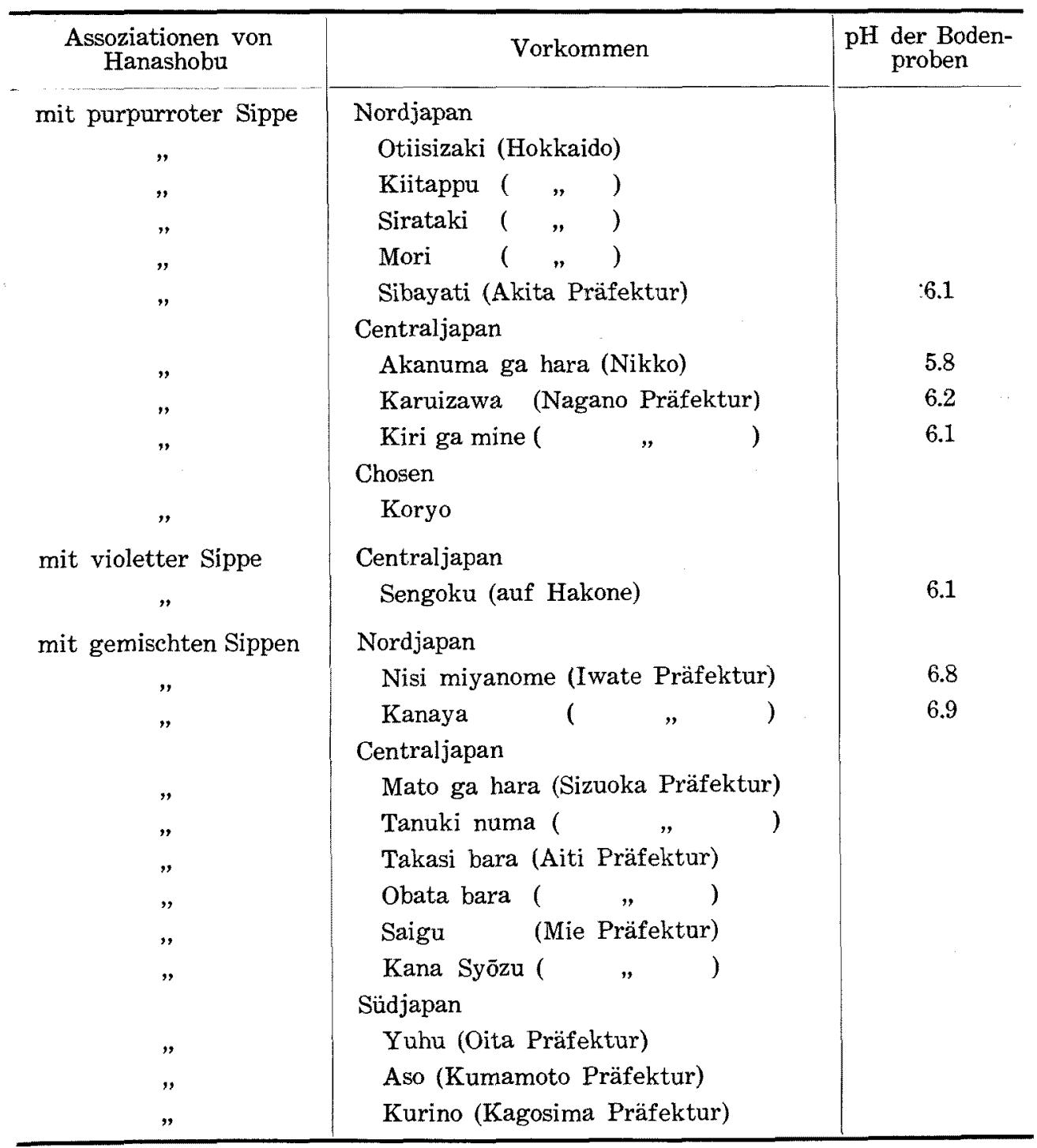

1) Proc. 10 (1934), 673. 
Wie oben angegeben, herrscht in Nordjapan auf Wiesen und Mooren vorwiegend die purpurrote Sippe, desgleichen auch in Centraljapan auf Bergwiesen und Bergmooren, während die reine violette Sippe bisher nur in der Berggegend Centraljapans gefunden worden ist. ${ }^{1}$

Anderseits sind gemischte Sippen in Central- und Südjapan allgemein, mit Ausnahme von einigen Stellen in Nordjapan (siehe die oben stehende Tabelle). Sie befinden sich jedoch nicht auf Bergen, sondern in Ebenen (Sümpfen und $\mathrm{Zwischenmooren)} \mathrm{wo} \mathrm{pH}$ beinahe neutral ist.

Diese Tatsachen zeigen, dass die purpurrote Sippe diejenigen Gegenden bevorzugt, die sich durch kühles und feuchtes Klima, sowie in gewissen Fällen durch Podsolböden auszeichnen. Ebenso auffallend ist die Verbreitung der violetten Sippe in wärmeren Teilen Japans bis zum südlichen Kyūsy $\bar{u}^{2)}$ und zwar gemischt mit der purpurroten Sippe in verschiedenen Farbenabstufungen.

Auf Grund der eigentlichen Verbreitungsweise ist es angebracht die Assoziationen mit der purpurroten Sippe als den nördlichen Typus, und die mit der violetten Sippe oder gemischten Sippen als den südlichen Typus anzusehen. Die erstere bedeckt ein weit grösseres Areal, als die letztere.

Da Hanashobu eigentlich zu borealen Floren gehört, scheint purpurrot die ursprüngliche Blütenfarbe, dagegen violett eine sekundäre zu sein.

Wenn diese Annahme zutrifft so dürfte meine frühere Ansicht $t^{3)}$ betreffs der Evolution der Blütenfarben der Hanashobu zu Recht bestehen.

Zum Schluss möchte ich betonen, dass die Farbenmerkmale der wilden Hanashobu-Blüten, wie meine Kulturversuche zeigen, grösstenteils erblich fixiert sind, und nicht lediglich klimatisch oder edaphisch, insbesondere durch Bodenazidität veränderlich sein können.

1) Miyoshi, M., Proc. 9 (1933), 410.

2) Die vor kurzem unter Naturschutz gestellte Hanashobu-Assoziation in Kurino, Kagosima Präfektur, welche wohl die südliche Grenze ihrer natürlichen Verbreitung darstellt, besteht mehr aus der violetten als aus der purpurroten Sippe.

3) Miyoshi, M., Erläuterungstext zu Album der Hanashobu 1920, übersetzt ins engliche von George M. Ried und Bunkio Matsuki. Bulletin of the American Iris Society, July 1932. 